\title{
Article \\ Reliability Verification of Existing RC Structures Using Partial Factors Approaches and Site-Specific Data
}

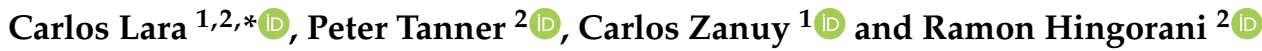 \\ 1 Escuela Técnica Superior de Ingenieros de Caminos, Canales y Puertos, \\ Universidad Politécnica de Madrid (UPM), C/Profesor Aranguren, 3, Ciudad Universitaria, \\ 28040 Madrid, Spain; carlos.zanuy@upm.es \\ 2 Instituto de Ciencias de la Construccion Eduardo Torroja (IETcc-CSIC), C/Serrano Galvache, 4, \\ 28033 Madrid, Spain; tannerp@ietcc.csic.es (P.T.); hingorani@ietcc.csic.es (R.H.) \\ * Correspondence: carloslara@ietcc.csic.es
}

Citation: Lara, C.; Tanner, P.; Zanuy, C.; Hingorani, R. Reliability Verification of Existing RC Structures Using Partial Factors Approaches and Site-Specific Data. Appl. Sci. 2021, 11, 1653. https://doi.org/10.3390/ app11041653

Academic Editor: Valerio De Biagi

Received: 6 January 2021

Accepted: 7 February 2021

Published: 12 February 2021

Publisher's Note: MDPI stays neutral with regard to jurisdictional claims in published maps and institutional affiliations.

Copyright: (c) 2021 by the authors. Licensee MDPI, Basel, Switzerland. This article is an open access article distributed under the terms and conditions of the Creative Commons Attribution (CC BY) license (https:/ / creativecommons.org/licenses/by/ $4.0 /)$.

\begin{abstract}
The assessment of an existing structure to determine its suitability for present and future use entails different sorts of problems than encountered when designing new structures. The differences revolve essentially around the nature of the information available. In existing structures, deteriorated or otherwise, the accuracy of the models used for such assessments can usually be improved by acquiring more data. The most accurate way to find actual load and resistance would be to conduct a probabilistic analysis using site data. This is a time-consuming process, however, calling for a working knowledge of probabilistic methods that may not be suited to everyday use by practising engineers. For this reason, in the past few years various studies have been conducted to develop assessment approaches, compatible with Eurocodes, which include the same verification format as normally applied for designing new structures. In this paper, the application of several of these approaches is illustrated by means of the reliability verification of one of the main beams of the reinforced concrete structure of an industrial building from the 1940s, recently transformed into a cultural centre. The obtained results are discussed and compared to the findings of a full probabilistic analysis.
\end{abstract}

Keywords: existing structures; reinforced concrete; assessment; reliability; probabilistic methods; partial factor method

\section{Introduction}

The main difference between assessing the performance of existing and designing new structures is that many characteristics whose values are merely anticipated in the latter can be measured in the former. The accuracy of the load and resistance models needed for the assessment can always be enhanced by collecting more data about the studied structure. Therefore, assessment is conducted by stages [1,2], raising the quality of the information available from stage to stage. The most accurate way to incorporate site data in structural safety verifications would be to conduct a probabilistic analysis. This is a time-consuming process, however, calling for a working knowledge of probabilistic methods that may not be suited to everyday use by practising engineers. For this reason, simplified methods for assessing the reliability of existing structures are normally applied. In such methods, based on the same partial factor formulation as adopted in structural design codes, the representative values for the variables and the partial factors can be modified on the basis of updated information.

Recently, various studies have been conducted to develop assessment approaches, compatible with the Eurocodes [3], that include the same verification format as normally applied for designing new structures and that allow for taking into account the influence of updated information on the characteristic values of the variables and the respective partial factors. A theoretical background and corresponding results for the safety assessment of existing structures, including a corresponding set of partial factors, were presented in [4]. 
Likewise, a set of partial factors specifically intended for use in reassessment of existing bridges under traffic load were derived in [5]. Probabilistic calculations were performed in [6] in order to calibrate adapted partial factors for assessment of existing concrete slab bridges under traffic load. The adapted partial factors are lower than the ones used for new concrete structures. Another study intended to clarify the applications of partial factors based on the semi-probabilistic approach to the verification of existing reinforced concrete bridges was carried out in [7].

Practical tools for reliability assessments of existing sound and deteriorated reinforced concrete (RC) structures using the partial factor method (PFM) have been developed by the authors in [8,9]. The issues addressed include the establishment of a target reliability level for existing building structures; the development of default probabilistic load and resistance models for reinforced concrete structures; a simplified procedure for modifying the parameters of these models, including the characteristic values of the corresponding variables, to accommodate updated information; and the determination of partial factors for assessment as a function of site-specific data. The procedures described in [8,9] may be used in the safety assessment of existing sound concrete building structures. Work has been undertaken to extend these tools to the assessment of corrosion-deteriorated structures. Nonetheless, further efforts are required to develop appropriate models for calculating the resistance of such structures, and calibrating the respective partial factors.

The fib Bulletin 80 [10] provides a basis for rational decision making with respect to safety-related issues associated with existing structures, as well as an extensive body of background information. Two simplified procedures for applying partial factor methods to the assessment of existing RC structures are proposed in [10]: The design value method (DVM) and the adjusted partial factor method (APFM). The general framework for both alternative approaches was presented in a publication prior to the fib Bulletin 80 [11]. The safety verification of existing RC structures by using the DVM, in accordance with $[3,12]$, was previously described in [13] as well. In this work, a numerical example supplements general procedures and illustrates how the design values and partial factors can be derived for different target reliability levels and remaining working lives. The application of the DVM and the APFM to the assessment of an existing prestressed concrete bridge is illustrated in $[14,15]$.

For the past few years, the CEN/TC 250 Working Group 2 has been engaged in the development of a Technical Specification (TS) on the Assessment of Existing Structures [2]. The TS establishes the PFM as the initial method for the verification of the structural safety of an existing structure. The partial factor format included in [2] is based on the assessment values of effects of actions and resistance, which are equivalent to the design values according to Eurocode [3]. The values of the design parameters are substituted by the corresponding values for assessment, taking into account the available information on the actual properties of the structure.

The main purpose of this paper is the presentation of a practical application of the aforementioned methods by means of the reliability verification of an existing beam belonging to an industrial reinforced concrete building. Before the practical application, a brief overview of the relevant theoretical studies serving as a basis for the assessment is presented in Section 2. In particular, the practical tools for reliability assessment of sound RC structures using PFM established by the authors are discussed in Section 2.2. The simplified methods DVM and APFM [10] are summarised in Section 2.3. Lastly, an overview of the TS approach [2] is provided in Section 2.4.

As a round robin exercise on the application of TS [2], experts of National Standardization Bodies (NSB) of eight CEN member states solved the example. The authors of this paper were responsible for the definition of the task including the input data. After the national experts had delivered their results, a sample solution was provided by applying the operational rules developed in $[8,9]$, which are compatible with the basic principles specified in [2]. Furthermore, the example was solved by the authors applying both partial factor approaches (DVM, APFM) proposed in [10]. The problem statement and the input 
data for the case study are presented in Section 3, while in Section 4 the verifications, carried out by applying the aforementioned approaches, are described and the outcomes discussed. In Section 5, a full probabilistic analysis is conducted for the beam cross-section considered and the results are compared to those obtained by applying the partial factor approaches. Conclusions from the application of the different methods are summarised in Section 6.

\section{Partial Factor Method for Reliability Verification}

\subsection{Design}

In most codes, the design values, $x_{i \mathrm{~d}}$, for variables $X_{i}$ are not considered directly [12] Rather, random variables with representative or characteristic values, $x_{\mathrm{k} i}$, are introduced in the model and the respective design values are obtained by applying a set of partial factors. In approximate analytical methods, such as First or Second Order Reliability Methods (FORM/SORM) [12], partial factors depend on:

- The partial factor format adopted;

- The chosen reference period;

- The representative values of the variables, $x_{\mathrm{k} i}$;

- The parameters (e.g., mean value, $\mu_{X i}$, standard deviation, $\sigma_{X i}$ ) and the type of distribution assumed for the variables, $X_{i}$;

- The target reliability index, $\beta_{t}$, for the limit state and the design situation at issue;

- The $\alpha_{i}$ factors describing the sensitivity to variations in $X_{i}$ with regard to attaining the considered limit state.

As indicated in [16], all this information should be related to the chosen reference period. In this context, it is important to keep in mind that the concepts of reference period and design working life (or remaining working life in case of assessment of an existing structure) are fundamentally different [3]. A reference period is a selected period of time for the assessment of the time-variant basic variables and probabilities of failure. The design (or remaining) working life is the period of time for which the structure is to be used without significant modifications or repair work being required.

\subsection{Assessment}

\subsubsection{Developed Tools}

When assessing the reliability of existing structures, updating information on a variable by gathering site-specific data to reduce the associated uncertainties affects both the characteristic value of the considered variable and the respective partial factor. For this reason, and in view of all the foregoing, the following issues have been addressed in a prior study to develop tools for the assessment of the reliability of existing sound structures, based on the partial factor method [9]:

- Identification of representative failure modes and the respective limit state functions (LSF);

- Definition of an appropriate reference period;

- Definition of target reliability levels (Section 2.2.2);

- Adoption of a partial factor format for the assessment of structural reliability (Section 2.2.3);

- For relevant variables $X_{i}$; according to the LSF considered, inference of default probabilistic models (e.g., parameters $\mu_{X i}, \sigma_{X i}$ and type of distribution) which may be used as prior information [8];

- Methods for updating of probabilistic distributions of basic variables-including updating of characteristic values, $x_{\mathrm{k} i, \mathrm{a}}$-and partial factors, $\gamma_{X i, \mathrm{a}}$, by combining sitespecific data with prior information, represented by the aforementioned default probabilistic models, for instance [9].

As for design of new structures, all information should be related to the chosen reference period. The choice of an adequate reference period often depends on the type of information available for updating the time-dependent variables [16]. This is the case, for instance, of climatic actions, like snow loads. In case site-specific data exists covering a 
sufficiently long period of time to enable the probability distribution of snow loads to be estimated over the remaining working life, snow loads may be updated on the basis of a statistical analysis where agreed by the relevant parties for a specific project [2].

\subsubsection{Target Reliability}

Structural acceptability should be determined by comparing the outcome of the assessment of an existing structure to established safety requirements as regards acceptable risks. The easiest and perhaps most logical approach is to establish the acceptable risks, and the corresponding reliability indices $\beta_{t}$, as the inherent risks associated with general state-of-the-art practice set out in modern structural standards [17-19], which are regarded to be acceptable by definition. The assessment tools developed in $[8,9]$ are based on that criterion and have been applied in the present study for the assessment of the existing RC beams (Sections 3 and 4). The partial factor format adopted for the assessment is described in the next subsection.

\subsubsection{Partial Factor Format for Assessment}

A cross-section, structural member or connection, is deemed to be structurally safe for its remaining service life if the following criterion holds in all significant hazard scenarios:

$$
E_{\mathrm{a}} \leq R_{a}
$$

For persistent and transient situations, the assessment value for the action effects, $E_{a}$, can be determined as follows:

$$
E_{\mathrm{a}}=\gamma_{S \mathrm{a}} \cdot E\left\{\sum_{j \geq 1} \gamma_{g \mathrm{a}, j} \cdot G_{k \mathrm{a}, j} ; \gamma_{p \mathrm{a}} \cdot P_{k \mathrm{a}} ; \gamma_{q \mathrm{a}, 1} \cdot Q_{k \mathrm{a}, 1} ; \sum_{i>1} \gamma_{q \mathrm{a}, i} \cdot \psi_{0, i} \cdot Q_{k a, i}\right\}
$$

where $G_{k a, j}, P_{k a}, Q_{k a, 1}, Q_{k a, i}$, respectively, represent the updated characteristic values for the permanent, prestressing, leading and accompanying variable actions; and $\gamma_{g a}, \gamma_{p a}, \gamma_{q a}$, represents the updated partial factors through which possible unfavourable deviations in the action values from the updated characteristic values are introduced in the model. With updated partial factor $\gamma_{s a}$, allowance is made for the uncertainties associated with the action effect models and the simplified representation of actions. Since model uncertainties vary depending on the action effects considered, in lieu of applying a single partial factor, $\gamma_{S a}$, as many factors are introduced as different action effects are to be calculated and are denoted as $\gamma_{S a, M}, \gamma_{S a, V}, \gamma_{S a, N}$ for, respectively, bending moments, shear forces and axial forces. Consequently, the partial factor format adopted to establish assessment values for action effects differs from standard code rules for structural design such as laid down in the Eurocodes [3]. However, this format is more accurate for assessment purposes.

The assessment value for ultimate resistance, $R_{\mathrm{a}}$, is determined by using updated characteristic values for material or product properties, $X_{k a, i}$, and updated assessment values for geometrical data, $a_{\mathrm{a}}$, equivalent to those defined in the Eurocodes [3]:

$$
R_{\mathrm{a}}=\frac{1}{\gamma_{R \mathrm{a}}} \cdot R\left\{\eta_{\mathrm{a} i} \cdot \frac{X_{k \mathrm{a}, i}}{\gamma_{m \mathrm{a}, i}} ; a_{\mathrm{a}}\right\} i \geq 1
$$

The partial factor for resistance is divided into the updated partial factors for material or product properties, $\gamma_{m a, i}$, and an updated partial factor associated with resistance model uncertainties, $\gamma_{R a}$. The latter also vary depending on the failure mechanism considered, which is why different $\gamma_{R a}$ factors are applied. In RC structures, for instance, different updated partial factors associated with resistance model uncertainties are defined for bending moments, $\gamma_{R a, M}$, tensile forces in the web, $\gamma_{R a, V s}$, diagonal compression forces in the web, $\gamma_{R a, V c}$, and axial compression forces, $\gamma_{R a, N}$. The criteria applicable to action effects also apply to the respective resistances: The partial factor format adopted to calculate the assessment value for ultimate resistance is a more accurate approach to assessment 
than the usual code formats used for design purposes [3]. Default values are used for most conversion factors for the effects of volume, scale, moisture or temperature on the material or product properties. Such factors may be updated $\left(\eta_{\mathrm{a} i}\right)$, however, if the necessary information is available. The partial factor format proposed here is compatible with the general principles proposed in [2] for determining $E_{\mathrm{a}}$ and $R_{\mathrm{a}}$, respectively (Section 2.4).

\subsubsection{Updating of Partial Factors}

In the assessment of the reliability of existing structures with site-specific models, partial factors are used in conjunction with characteristic action and resistance values. Updating information about a variable by gathering site-specific data to reduce the associated uncertainties affects both the characteristic value of the variable considered and the respective partial factor. The effect of this change of information on the characteristic value can be deduced by applying statistical methods to the experimental results found and using any previously available information. The procedure for applying site-specific models is described in [9]. Appropriate assumptions about the type of distributions used for the different basic variables in most applications can be found in [16]. Furthermore, examples of how the updated partial factors can be obtained for variables that obey these types of distributions are also shown in [16].

\subsection{Reliability Verification by PFM in fib Bulletin 80}

\subsubsection{General}

Both partial factor formats provided in [10]—-the DVM and the APFM—enable the incorporation of specific reliability-related aspects for existing structures. The DVM proposes a fundamental basis for evaluating partial factors, whereas the APFM provides adjustment factors to be applied to the partial factors for new structures in [3]. The two alternative methods are briefly explained in the following.

\subsubsection{Design Value Method}

The DVM consists in the application of the partial factor method recommended in the Eurocode for new structures [3], but allowing to derive the partial factors $\gamma_{X}$ from the actual distribution of the variable $X$ under consideration (based on prior information, results of tests or the combination of both). Furthermore, the partial factors can be established taking into account case-specific target reliability levels and the remaining working life for existing structures.

\subsubsection{Adjusted Partial Factor Method}

According to [10] the basic philosophy of the APFM consists in calculating adjusted partial factors $\gamma_{X}$ for the variables $X$ related with an existing structure, considering alternative values for, respectively, the reference period, $t_{\text {ref }}$, the target reliability index, $\beta_{t}$, and the coefficient of variation, $V_{X}$, of the variable under consideration. For a given variable $X$, this adjusted partial factor is obtained by multiplying the partial factor $\gamma_{X \text {,new }}$ provided in the Eurocodes for new structures [3] by an adjustment factor $\omega_{\gamma}$ :

$$
\gamma_{X}=\omega_{\gamma}\left(t_{\text {ref }}, \beta_{t}, V_{X}\right) \cdot \gamma_{X, \text { new }}
$$

For the adjustment of partial factors with respect to variable actions, two methods are distinguished in [10]: A and B. The difference between the two methods relates to the way in which the reference period of the existing structure is incorporated. In method A, this effect is included in the adjustment factor, whereas in method B the effect is incorporated in the derivation of alternative characteristic values for the variable actions.

\subsection{Reliability Verification by PFM in CEN TS}

According to the European (European Committee for Standardization, CEN) Technical Specification [2], the assessment of an existing structure should initially be carried out 
using PFM. After this method has been utilised, the assessment value method, probabilistic methods and the risk assessment method can be used subsequently for:

- Overcoming the conservatism of partial factor methods;

- Cases of structural failures with serious consequences;

- Cases of insufficient robustness;

- Evaluating the efficiency of monitoring and maintenance strategies;

- Making fundamental decisions concerning a whole group of structures.

When using the PFM, the TS [2] indicates that the inequality given by Formula (1) shall by verified. The assessment value of the effect of actions $E_{a}$ should be determined in the same way as for the design value $E_{d}$ according to [3], but substituting the values of design parameters (including basic variables, partial factors and combination factors applied to actions $\psi$ ), by the corresponding values for assessment, if available. Likewise, the assessment value of resistance $R_{a}$ should be determined in the same way as for the design value $R_{d}$ in [3], but substituting, as far as possible, the values of design parameters (including basic variables, partial factors for materials and conversion factors), by the corresponding values for assessment.

\section{Problem Statement}

The transformation of an industrial building from the 1940s into a cultural centre requires the reliability verification of the reinforced concrete structure for the future use conditions. The building is located in the northwest coast of Spain and is exposed to a severe marine environment. The existing structure has been abandoned for 20 years and shows significant corrosion damage, in particular with regard to the secondary structural elements as well as the non-structural elements. Figure 1 shows the condition of the existing building before the transformation.

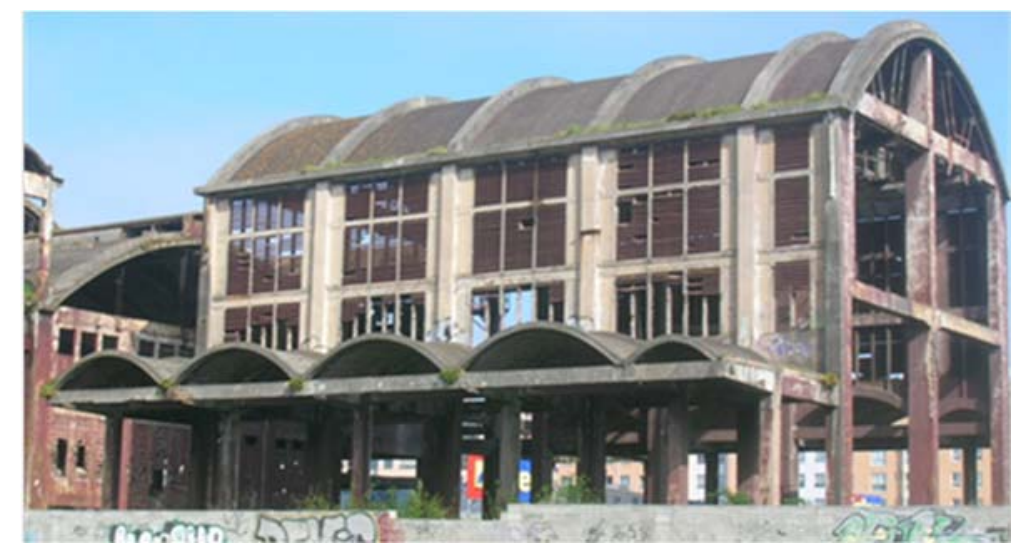

Figure 1. Condition of the industrial building before transformation (photo courtesy of Diaz \& Diaz Architects S.L.).

Due to architectural requirements, non-structural and secondary structural elements were demolished. The aim was to integrate most of the existing main structural elements, repaired if deteriorated (Figure 2), into the load bearing system of the transformed building. Reliability verification was therefore required for these existing structural members, taking into account the properties of the transformed building and its future use. The planned transformation of the building is represented in Figure 3. 


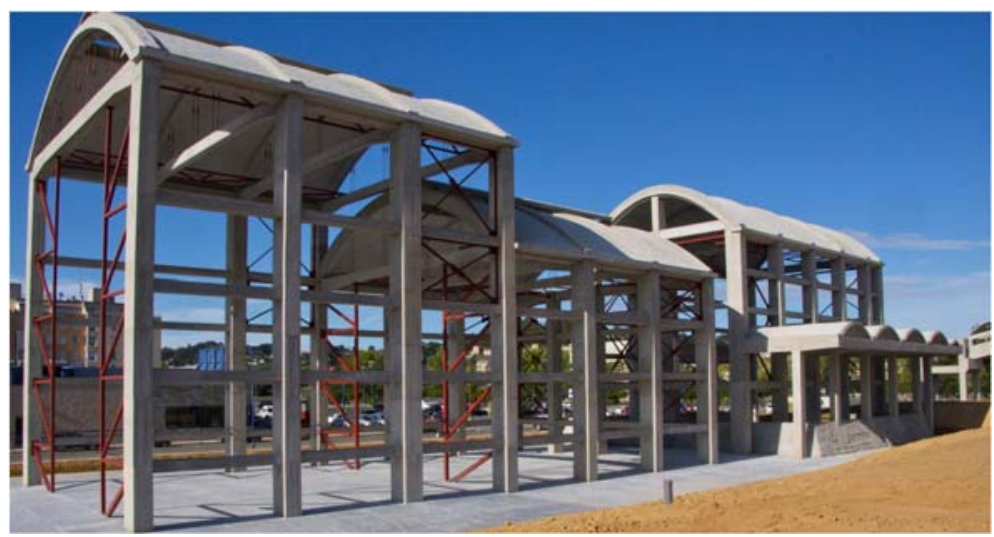

Figure 2. General view of the structure after repair (photo courtesy of Diaz \& Diaz Architects S.L.).

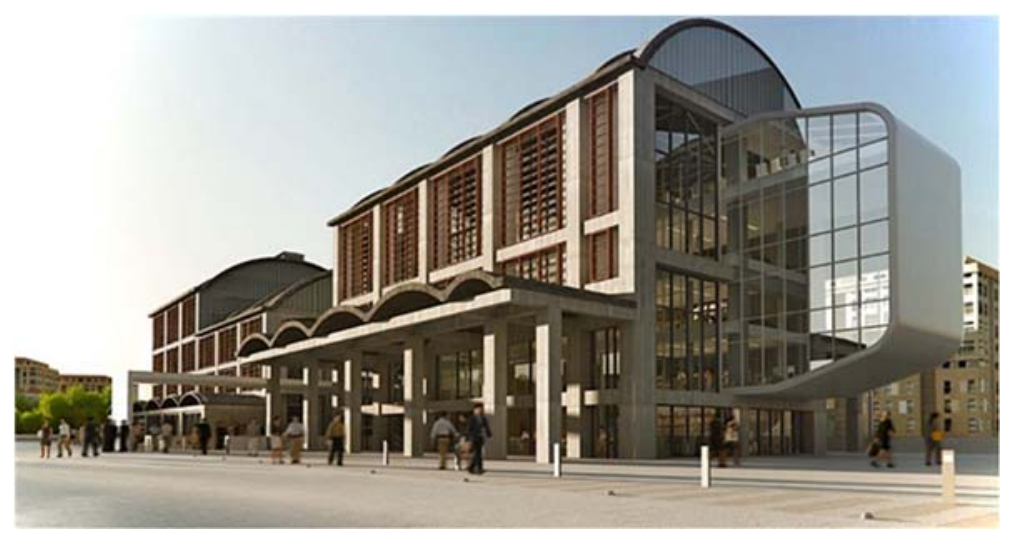

Figure 3. Final condition of the building (rendering courtesy of Diaz \& Diaz Architects S.L.).

In the present application example, the structural safety of one of the existing floor beams should be verified. For sake of simplicity, the only limit state considered in this contribution is that associated with bending failure at mid-span. The beams are simply supported, with $6 \mathrm{~m}$ span length, and their centre-to-centre distance is $5 \mathrm{~m}$. After the demolition of the existing slabs, new lightweight floors will be installed, supported by the existing main beams. No shear connection will be provided between these beams and the new floor.

After the transformation of the building, the characteristic value of the permanent load due to the self-weight of the new floor, partition walls, etc., will reach $g_{k}=2 \mathrm{kN} / \mathrm{m}^{2}$. The floor system, including the beams to be assessed, belongs to an area with fixed seats. The remaining working life of the transformed structure is 50 years. A staged assessment procedure based on the PFM should be carried out. The existing beams should be assessed taking into account their actual conditions after repair, i.e., no deterioration needs to be considered, and the intended use of the corresponding building area.

\section{Verification Based on PFM}

\subsection{First Stage}

4.1.1. Input

For the first stage, site information is obtained by investigating a limited number of the demolished secondary members of the same building, with material characteristics that are considered representative for the assessment of the main structural elements. Site-specific characteristics of concrete and reinforcing steel are established based on the information gathered. The obtained sample parameters (mean value, $f_{c m}$, standard deviation, $\sigma_{f c}$, and coefficient of variation $V_{f_{c}}$ ) of the concrete compressive strength, $f_{c}$, are summarised in Table 1. 
Table 1. First stage sample parameters for concrete compressive strength.

\begin{tabular}{lcccc}
\hline Source & Number of Tests & $f_{c m}\left[\mathbf{N} / \mathbf{m m}^{2}\right]$ & $\sigma_{f_{c}}\left[\mathbf{N} / \mathbf{m m}^{2}\right]$ & $V_{f_{c}}$ \\
\hline $\begin{array}{l}\text { Secondary } \\
\text { elements }\end{array}$ & 6 & 27.3 & 9.7 & 0.36 \\
\hline
\end{tabular}

Table 2 contains the mean, $f_{y m}$, and the coefficient of variation, $V_{f y}$, of the reinforcing steel yield strength, $f_{y}$. For both, $f_{c}$ and $f_{y}$, the coefficients of variation associated with structures designed and built according to former code rules are available [20]. These coefficients of variation are, $V_{f c}=0.25$ and $V_{f y}=0.10$, respectively, and can be adopted as prior information.

Table 2. First stage sample parameters for reinforcing steel yield strength.

\begin{tabular}{lcccc}
\hline Source & Diameter $[\mathrm{mm}]$ & Number of Tests & $f_{y m}\left[\mathbf{N} / \mathbf{m m}^{2}\right]$ & $V_{f m}$ \\
\hline $\begin{array}{l}\text { Secondary } \\
\text { elements }\end{array}$ & 20 & 3 & 219 & 0.05 \\
\hline
\end{tabular}

Geometry of the demolished secondary structural members is also established. As a result, it can be assumed that cross-sectional dimensions correspond to nominal values, with deviations which are of the same order of magnitude as modern construction tolerances. Cross-section geometry of the studied main beam is defined in Figure 4.

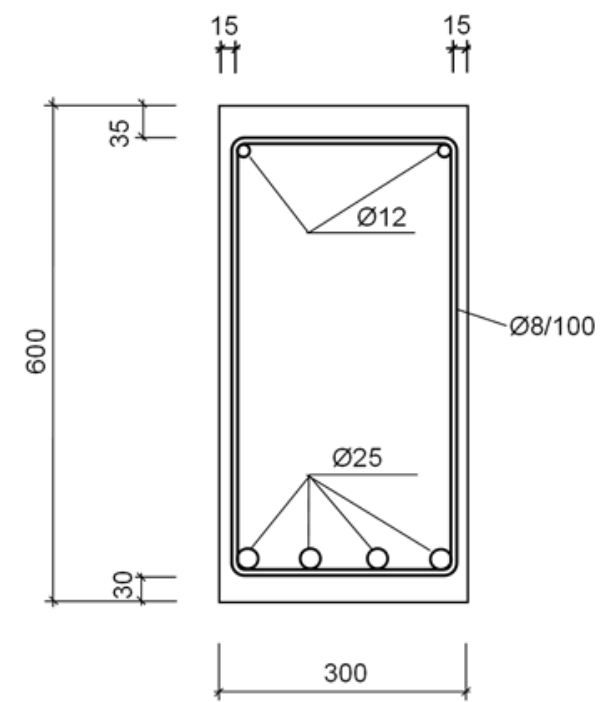

Figure 4. Beam cross-section (mm).

\subsubsection{Applied Parameters for Basic Variables and Partial Factors}

The characteristic values and partial factors applied by the experts of the eight CEN member states, that have solved the example in the round exercise, were adopted taking into account the site-specific data, and established according to relevant Eurocodes and Nationally Determined Parameters (NDPs).

Parameters for the different variables listed in Table 3 were used in the first stage of the assessment by applying the procedure developed in [9]. The parameters for the concrete compressive strength, $f_{c}$, and yield strength of reinforcement, $f_{y}$, have been updated according to the procedure included in [2,12], by combining the information from the former code [20] with the test results (Tables 1 and 2). For the other basic variables involved in the assessment, default probabilistic models were adopted in accordance with the models in [8]. 
Table 3. First stage probabilistic models for basic variables adopted for the assessment according to [9].

\begin{tabular}{|c|c|c|c|c|c|}
\hline Variable & Distribution & $X$ & $X_{k}$ & $V_{X}$ & $\mu_{X} / X_{k}$ \\
\hline Self-weight of concrete, $\mathrm{kN} / \mathrm{m}^{3}$ & $\mathrm{~N}$ & $g_{c}$ & 25 & 0.04 & 1.0 \\
\hline Other permanent loads, $\mathrm{kN} / \mathrm{m}^{2}$ & $\mathrm{~N}$ & $g_{p}$ & 219 & 0.05 & 1.0 \\
\hline Imposed load, $\mathrm{kN} / \mathrm{m}^{2}$ & Gum & $q_{\text {imp }}$ & 4.0 & 0.26 & 0.68 \\
\hline $\begin{array}{l}\text { Model uncertainty for load } \\
\text { effect (bending moments) }\end{array}$ & LN & $\xi_{E, M}$ & - & 0.10 & 1.0 \\
\hline $\begin{array}{l}\text { Concrete compressive strength, } \\
\mathrm{N} / \mathrm{mm}^{2}\end{array}$ & LN & $f_{c}$ & $16.5^{1}$ & $0.25^{1}$ & $1.61^{1}$ \\
\hline $\begin{array}{l}\text { Yield strength of reinforcement, } \\
\mathrm{N} / \mathrm{mm}^{2}\end{array}$ & LN & $f_{y}$ & $181^{1}$ & $0.10^{1}$ & $1.21^{1}$ \\
\hline $\begin{array}{l}\text { Effective depth of mid span } \\
\text { cross-section, } \mathrm{mm}\end{array}$ & $\mathrm{N}$ & $d$ & 549.5 & 0.04 & 1.00 \\
\hline Cross-section width, mm & $\mathrm{N}$ & $b$ & 300 & 0.03 & 1.00 \\
\hline $\begin{array}{l}\text { Cross sectional area of } \\
\text { reinforcement, } \mathrm{mm}^{2}\end{array}$ & $\mathrm{~N}$ & $A_{S}$ & 1963 & 0.02 & 1.00 \\
\hline $\begin{array}{l}\text { Uncertainty of bending } \\
\text { resistance model }\end{array}$ & LN & $\xi_{R, M}$ & - & 0.064 & 1.00 \\
\hline
\end{tabular}

${ }^{1}$ Updated according to $[2,12]$.

For solving the example according to both partial factors approaches provided by the fib Bulletin 80 [10], DVM and APFM, the parameters for the different variables have been established following the recommendations given in the same document. These parameters are listed in Table 4 . The updated models for $f_{c}$ and $f_{y}$, listed in Table 3 , were applied for both partial factors approaches as well.

Table 4. First stage probabilistic models for basic variables adopted for the assessment according to fib Bulletin 80 [10].

\begin{tabular}{|c|c|c|c|c|c|c|c|c|}
\hline \multirow{2}{*}{\multicolumn{2}{|c|}{ Variable }} & \multirow{2}{*}{ Distribution } & \multirow{2}{*}{$X$} & \multicolumn{3}{|c|}{ DVM } & \multicolumn{2}{|c|}{ APFM } \\
\hline & & & & $X_{k}$ & $V_{X}$ & $\mu_{X} / X_{k}$ & $X_{k}$ & $V_{X}$ \\
\hline \multicolumn{2}{|c|}{ Self-weight of concrete, $\mathrm{kN} / \mathrm{m}^{3}$} & $\mathrm{~N}$ & $g_{c}$ & 25 & 0.05 & 1.0 & 25 & \multirow{2}{*}{0.10} \\
\hline \multicolumn{2}{|c|}{ Other permanent loads, $\mathrm{kN} / \mathrm{m}^{2}$} & $\mathrm{~N}$ & $g_{p}$ & 2.0 & 0.10 & 1.0 & 2.0 & \\
\hline \multicolumn{2}{|c|}{ Imposed load, $\mathrm{kN} / \mathrm{m}^{2}$} & Gum & $q_{\text {imp }}$ & 4.0 & 0.26 & 0.68 & 4.0 & $0.25^{1}$ \\
\hline \multirow{2}{*}{$\begin{array}{l}\text { Model uncertainty for } \\
\text { load effect (bending } \\
\text { moments) }\end{array}$} & For permanent actions & $\mathrm{LN}$ & $\theta_{E, M, G}$ & \multirow{2}{*}{-} & \multirow{2}{*}{0.10} & \multirow{2}{*}{1.0} & \multirow{2}{*}{-} & 0.065 \\
\hline & For variable actions & $\mathrm{LN}$ & $\theta_{E, M, Q}$ & & & & & 0.11 \\
\hline \multicolumn{2}{|c|}{ Concrete compressive strength, $\mathrm{N} / \mathrm{mm}^{2}$} & $\mathrm{LN}$ & $f_{c}$ & $16.5^{2}$ & $0.25^{2}$ & $1.61^{2}$ & $16.5^{2}$ & $0.25^{2}$ \\
\hline \multicolumn{2}{|c|}{ Yield strength of reinforcement, $\mathrm{N} / \mathrm{mm}^{2}$} & LN & $f_{y}$ & $181^{2}$ & $0.10^{2}$ & $1.21^{2}$ & $181.0^{2}$ & $0.10^{2}$ \\
\hline \multicolumn{2}{|c|}{ Effective depth of mid span cross-section, mm } & Det & $d$ & 549.5 & - & - & 549.5 & - \\
\hline \multicolumn{2}{|l|}{ Cross-section width, mm } & Det & $b$ & 300 & - & - & 300 & - \\
\hline \multicolumn{2}{|c|}{ Cross sectional area of reinforcement, $\mathrm{mm}^{2}$} & Det & $A_{S}$ & 1963 & - & - & 1963 & - \\
\hline \multirow{4}{*}{$\begin{array}{l}\text { Uncertainty of bending } \\
\text { resistance model }\end{array}$} & \multirow{2}{*}{ For concrete } & \multirow{2}{*}{$\mathrm{LN}$} & \multirow{2}{*}{$\theta_{R, M, c}$} & \multirow{2}{*}{-} & \multirow{2}{*}{0.08} & \multirow{2}{*}{1.0} & - & $0.075^{3}$ \\
\hline & & & & & & & - & $0.075^{4}$ \\
\hline & \multirow{2}{*}{ For reinforcing steel } & \multirow{2}{*}{ LN } & \multirow{2}{*}{$\theta_{R, M, s}$} & & \multirow{2}{*}{0.02} & \multirow{2}{*}{1.0} & - & $0.02^{3}$ \\
\hline & & & & & & & - & $0.04^{4}$ \\
\hline
\end{tabular}

${ }^{1}$ Default value for the reference period of 50 years. ${ }^{2}$ Updated according to [2,12]. ${ }^{3}$ Accounting for model uncertainty [10]. ${ }^{4}$ Accounting for geometrical uncertainties [10].

According to the APFM, the variable parameters related to new structures are designated with ' and those for existing structures with ". Hence, $V_{X}$ ' and $V_{X}$ " represent the coefficients of variation of variable $X$ related to new and existing structures, respectively. The values for new structures, suggested in [10], for the coefficients of variation, $V_{c}{ }^{\prime}=0.15$ and $V_{s}{ }^{\prime}=0.05$, respectively, have been adopted. In this way, the limiting conditions for the application of the method, regarding the coefficients of variation, $\left(V_{s}{ }^{\prime \prime} / V_{s}{ }^{\prime}\right)_{\min }=0.8$ 
and $\left(V_{c}{ }^{\prime \prime} / V_{c}\right)_{\min }=0.5$, so that the uncertainty of model resistance could not become the dominant variable, are fulfilled. The probabilistic models for the action variables have been assumed in line with the indications for the DVM and APFM. For the latter, the default values suggested in [10] have been adopted, taking into account, in addition, the following assumptions: $V_{G}{ }^{\prime \prime}=V_{G^{\prime}}{ }^{\prime}, V_{Q i m p, 50 "}=V_{Q i m p, 50^{\prime}}, V_{\theta, E, G}{ }^{\prime \prime}=V_{\theta, E, G^{\prime}}$ and $V_{\theta, E, Q^{\prime \prime}}=V_{\theta, E, Q^{\prime}}$, for permanent actions, imposed loads and model uncertainties for permanent and variables actions, respectively.

The partial factors resulting from the application of the probabilistic models and procedures included in $[9,10]$, together with the probabilistic models previously discussed (Tables 3 and 4), are indicated in Table 5 . The assumed target reliability indices, $\beta_{t}$, and characteristic values of the imposed load, $q_{k}$, are indicated in Table 6 . The values for $\beta_{t}$ have been adopted following the indications of [2], Eurocode [3], National Standards of the CEN member states, as well as other considerations (e.g., based on risk analysis). For applying the fib Bulletin 80 [10], the target reliability index for upgrading, $\beta_{\mathrm{up}, t}$, was assumed, as a function of the collapsed area $A_{\mathrm{col}}=30 \mathrm{~m}^{2}$ and the remaining working life of the transformed structure. Regarding $q_{\mathrm{k}}$, the recommendations of the Eurocode [21] together with NDPs have been considered.

Table 5. Partial factors for the first stage of the assessment.

\begin{tabular}{|c|c|c|c|c|c|}
\hline \multirow{2}{*}{ Variables } & \multirow{2}{*}{ Symbol } & \multirow{2}{*}{$\begin{array}{l}\text { [9] procedure } \\
\text { Partial Factor }\end{array}$} & \multirow{2}{*}{$\begin{array}{c}\text { DVM [10] } \\
\text { Partial Factor }\end{array}$} & \multicolumn{2}{|c|}{ APFM [10] } \\
\hline & & & & Adjustment Factor & Partial Factor 1 \\
\hline \multirow{10}{*}{ Actions } & $\gamma_{g c, 1}$ & & 1.13 & - & - \\
\hline & $\gamma_{g p, 1}$ & & 1.27 & - & - \\
\hline & $\gamma_{q, 1}$ & & 1.37 & - & - \\
\hline & $\gamma_{S a, M, 1}$ & & 1.11 & - & - \\
\hline & $\omega_{\gamma, G, 1}$ & & - & 0.96 & - \\
\hline & $\omega_{\gamma, Q, 1}$ & & - & 0.89 & - \\
\hline & $\gamma_{G c, 1}$ & & 1.25 & - & - \\
\hline & $\gamma_{G p, 1}$ & & 1.41 & - & - \\
\hline & $\gamma_{G, 1}$ & 1.35 & - & - & 1.30 \\
\hline & $\gamma_{Q, 1}$ & 1.5 & 1.52 & - & 1.34 \\
\hline \multirow{8}{*}{ Material properties } & $\gamma_{s, 1}$ & 1.13 & 1.15 & - & - \\
\hline & $\gamma_{R a, s, 1}$ & 1.08 & 1.02 & - & - \\
\hline & $\gamma_{c, 1}$ & 1.0 & 1.42 & - & - \\
\hline & $\gamma_{R a, c, 1}$ & 1.08 & 1.1 & - & - \\
\hline & $\omega_{\gamma, S, 1}$ & & - & 1.04 & - \\
\hline & $\omega_{\gamma, C, 1}$ & & - & 1.05 & - \\
\hline & $\gamma_{S, 1}$ & 1.22 & 1.17 & - & 1.20 \\
\hline & $\gamma_{C, 1}$ & 1.08 & 1.56 & - & 1.58 \\
\hline
\end{tabular}

${ }^{1}$ Indicated values were updated based on partial factors for new structures as indicated in the Eurocodes.

Table 6. First stage target reliability indices, characteristic values for imposed loads and assessment values for bending moment and resistance.

\begin{tabular}{|c|c|c|c|c|c|c|}
\hline Approaches & & $\beta_{\mathrm{t}}$ & $q_{\mathrm{k}}\left[\mathrm{kN} / \mathrm{m}^{2}\right]$ & $M_{E a, 1}[\mathrm{kNm}]$ & $M_{R a, 1}[\mathrm{kNm}]$ & $M_{E a, 1} \leq M_{R a, 1}$ \\
\hline \multirow{8}{*}{$\begin{array}{l}\text { NSB of CEN Member } \\
\text { states [2] }\end{array}$} & NSB1 & 3.8 & 5.0 & 230.0 & 155.0 & No \\
\hline & NSB2 & 3.3 & 5.0 & 256.0 & 159.0 & No \\
\hline & NSB3 & 3.5 & 4.0 & 223.2 & 131.0 & No \\
\hline & NSB4 & 3.8 & 4.0 & 223.0 & 156.0 & No \\
\hline & NSB5 & 3.8 & 4.0 & 217.0 & 183.0 & No \\
\hline & NSB6 & 3.8 & 4.0 & 212.0 & 197.0 & No \\
\hline & NSB7 & 3.3 & 5.0 & 229.5 & 191.9 & No \\
\hline & NSB8 & 4.0 & 4.0 & 214.0 & 179.0 & No \\
\hline
\end{tabular}


Table 6. Cont.

\begin{tabular}{llcccccc}
\hline Approaches & & $\beta_{\mathrm{t}}$ & $q_{\mathrm{k}}\left[\mathbf{k N} / \mathbf{m}^{\mathbf{2}}\right]$ & $\boldsymbol{M}_{E \boldsymbol{a}, \mathbf{1}}[\mathbf{k N m}]$ & $\boldsymbol{M}_{\boldsymbol{R} a, \mathbf{1}}[\mathbf{k N m}]$ & $\boldsymbol{M}_{E a, \mathbf{1}} \leq \boldsymbol{M}_{\boldsymbol{R} a, \mathbf{1}}$ \\
\hline [9] procedure & & 3.8 & 4.0 & 223.1 & 150.7 & No \\
\hline \multirow{2}{*}{ fib Bulletin 80 [10] } & DVM & 3.8 & 4.0 & 225.6 & 152.3 & No \\
\cline { 2 - 8 } & APFM & 3.8 & 4.0 & 205.4 & 149.1 & No \\
\hline
\end{tabular}

\subsubsection{Results}

From Table 6 can be observed that structural safety is not verified for any of the partial factor approaches applied; moreover, in the case of the TS [2], the results obtained by all of the NSBs do not satisfy the safety requirements. Therefore, a second stage with updated information would be necessary. It can be also observed, from Table 6, that the results obtained for the assessment values of the effects of actions (bending moments), $M_{E, a, 1}$, show a relatively slight variation, while the assessment values of resistance, $M_{R a, 1}$, show more significant variations. The small variation in the values of $M_{E, a, 1}$ can be explained taking into account that both the characteristic values of actions and their probabilistic models, that were used for the deduction of partial factors, have not been derived from site-specific data but were adopted according to the recommendations of $[2,3,8,10,21]$ or NDPs of CEN member states.

Regarding $M_{R, a, 1}$, large differences appear between the results obtained by the different CEN member states based on TS [2]; whereas the values resulting from the application of the tools developed in [9] and the two approaches proposed by [10] are quite similar. The large differences between the results for $M_{R a, 1}$ obtained by the experts of CEN member states are mainly due to the assumptions for the prior information, the procedures that have been used for updating the models for $f_{y}$ and $f_{c}$, as well as the characteristic values adopted for these material properties. Particularly, in the case of the NSB3 a comparatively low value for $M_{R a, 1}$ has been obtained. This is due to the fact that the characteristic values for $f_{c}$ and $f_{y}$ have been determined from the sample parameters, according to [12], without taking into account the prior information, available from the former code [20]. The second reason for this low $M_{R a, 1}$ value was that the corresponding partial factors have not been updated and that the values for new structures, according to [22], have been applied instead. On the contrary, a much higher value of $M_{R a, 1}=197.0 \mathrm{kNm}$ was obtained by the NSB6, since the test results listed in Tables 1 and 2 were ignored by considering that they are not representative. Instead, data from Table 7 (second stage) were used to determine the characteristic value for concrete compressive strength, and the characteristic value for the yield strength of reinforcement was assumed based on the available specification that was in force at the time of the building construction.

Table 7. Sample parameters for concrete compressive strength.

\begin{tabular}{lccccc}
\hline Source & Number of Tests & $f_{c m}\left[\mathbf{N} / \mathbf{m m}^{2}\right]$ & $\sigma_{f_{c}}\left[\mathbf{N} / \mathbf{m m}^{2}\right]$ & $V_{f_{c}}$ & $f_{c k}\left[\mathbf{N} / \mathrm{mm}^{2}\right]$ \\
\hline Main beams & 4 & 25.9 & 2.4 & 0.09 & 20.1 \\
\hline
\end{tabular}

\subsection{Second Stage}

\subsubsection{Additional Information}

Since in the first stage structural safety was not verified by applying any of the partial factor approaches considered, a second assessment stage is performed. For this purpose, additional information about the material properties was obtained directly from the investigated main beams. Tensile tests were conducted on four steel specimens fabricated from samples extracted from one $25 \mathrm{~mm}$ diameter reinforcing bar, in order to minimise destructive material testing. The following values were measured for the reinforcing steel yield strength: $\mathbf{f}_{\mathbf{y}}=\{312 ; 301 ; 308 ; 306\} \mathrm{N} / \mathrm{mm}^{2}$. The sample parameters obtained from the tensile test results are shown in Table 8 . Likewise, compressive tests were conducted on 
four cores drilled in the main beams to determine the concrete compressive strength. The new information for concrete compressive strength is summarised in Table 7.

Table 8. Sample parameters for reinforcing steel yield strength.

\begin{tabular}{lcccc}
\hline Source & Number of Tests & $f_{y m}\left[\mathbf{N} / \mathrm{mm}^{2}\right]$ & $V_{f y}$ & $f_{y k}\left[\mathbf{N} / \mathbf{m m}^{2}\right]$ \\
\hline Main beams & 4 & 307 & 0.01 & 299 \\
\hline
\end{tabular}

Using the additional information, the parameters for $f_{c}$ and $f_{y}$ have been updated by combination, following the procedure included in $[2,12]$, with the results from the first stage (Table 4). The updated probabilistic models for these two variables are indicated in Table 9. They were used for the reliability verification applying the procedure included in [9] as well as for the DVM and the APFM [10]. As in the first stage, the prior values, suggested in [10], for the coefficients of variation related to new structures, $V_{c}{ }^{\prime}=0.15$ and $V_{s}^{\prime}=0.05$, respectively, were adopted. For all other variables, the same probabilistic models as in the first stage (Tables 3 and 4 ) were used when applying the procedure developed in [9] and the two approaches proposed in fib Bulletin 80 [10], respectively.

Table 9. Second stage updated probabilistic models.

\begin{tabular}{lccccc}
\hline Variable & Distribution & $X$ & $X_{k}\left[\mathbf{N} / \mathbf{m m}^{2}\right]$ & $V_{X}$ & $\mu_{X} / X_{k}$ \\
\hline $\begin{array}{l}\text { Yield strength of } \\
\text { reinforcement }\end{array}$ & LN & $f_{y}$ & 260.4 & 0.08 & 1.18 \\
\hline $\begin{array}{l}\text { Concrete compressive } \\
\text { strength }\end{array}$ & LN & $f_{c}$ & 16.8 & 0.21 & 1.57 \\
\hline
\end{tabular}

\subsubsection{Results}

The updated partial factors for the resistance variables used in the second stage of the assessment procedures according to $[9,10]$ are indicated in Table 10. They were derived by applying the models described in the previous section. Since the probabilistic models for the actions were not updated, the same partial factors as in the first stage were used (Table 5). As can be observed from Table 10, the partial factor $\gamma_{s, 2}$ deduced by applying [9] is smaller than the obtained in the first stage, $\gamma_{s, 1}$, which is explained by the reduction in the coefficient of variation, as a result of updating information. For the same reason, the partial factors for the material properties derived according to the DVM [10] are also smaller than the obtained in the first stage. Likewise, the values for $\gamma_{S, 2}$ and $\gamma_{C, 2}$, obtained according to the APFM, are smaller than the derived in the first stage.

Table 10. Partial factors for resistance variables used in the second stage of the assessment.

\begin{tabular}{lcccc}
\hline \multirow{2}{*}{ Symbol } & [9] Procedure & DVM [10] & \multicolumn{2}{c}{ APFM [10] } \\
\cline { 2 - 5 } & Partial Factor & Partial Factor & Adjustment Factor & Partial Factor \\
\hline$\gamma_{s, 2}$ & 1.09 & 1.12 & - & - \\
$\gamma_{R a, s, 2}$ & 1.08 & 1.02 & - & - \\
$\gamma_{c, 2}$ & 1.0 & 1.34 & - & - \\
$\gamma_{R a, c, 2}$ & 1.08 & 1.1 & - & - \\
$\omega_{\gamma, S, 2}$ & - & - & 1.00 & - \\
$\omega_{\gamma, C, 2}$ & - & - & 1.00 & 1.15 \\
$\gamma_{S, 2}$ & 1.18 & 1.14 & - & 1.50 \\
$\gamma_{C, 2}$ & 1.08 & 1.47 & - & \\
\hline
\end{tabular}

The outcomes for the assessment values of the effect of actions and resistance are shown in Table 11. As can be seen, the beam reliability is verified by the experts of five of the CEN member states and also by applying the APFM. On the contrary, reliability can neither be verified based on the application of the tools and procedure proposed in [9], 
nor on the DVM [10]. The results obtained by applying both procedures are indeed very similar. Consequently, for this application example, the results obtained with the DVM and the APFM do not agree with indications in [10], according to which the latter is often more conservative than the former. For all other cases, although the beam reliability is not verified, the difference between the assessment value for bending moment $M_{\mathrm{Ea}, 2}$ and the assessment value of resistance $M_{R \mathrm{a}, 2}$ is not greater than $6 \%$, except for the NSB4.

Table 11. Second stage assessment values for bending moments and resistance.

\begin{tabular}{lcccc}
\hline Approaches & & $\boldsymbol{M}_{E a, \mathbf{2}}[\mathbf{k N m}]$ & $\boldsymbol{M}_{\boldsymbol{R} a, \mathbf{2}}[\mathbf{k N m}]$ & $\boldsymbol{M}_{E \boldsymbol{a}, \mathbf{2}} \leq \boldsymbol{M}_{\boldsymbol{R} a, \mathbf{2}}$ \\
\hline & NSB1 & 230.0 & 216.5 & No \\
& NSB2 & & Not carried out & Yes \\
NSB of CEN & NSB3 & 223.2 & 265.0 & No \\
Member states [2] & NSB4 & 223.0 & 163.0 & Yes \\
& NSB5 & 217.0 & 250.0 & Yes \\
& NSB6 & 212.0 & 230.0 & Yes \\
& NSB7 & 229.5 & 288.7 & Yes \\
\hline [9] procedure & NSB8 & 207.0 & 214.0 & No \\
\hline \multirow{2}{*}{ fib Bulletin 80 [10] } & & 223.1 & 218.4 & No \\
\cline { 2 - 5 } & DVM & 225.6 & 217.0 & Yes \\
\hline
\end{tabular}

The significant differences between the results for $M_{R \mathrm{a}, 2}$ obtained by the experts of CEN members states are mainly due to the same reasons as previously outlined for the first stage. From Table 11 can be observed that the assessment value of the bending resistance obtained by the NSB4 is significantly lower than the other results. It has slightly rised from 156.0 in the first stage to $163.0 \mathrm{kNm}$ in the second. This is explained by the fact that the expert has not taken into account the data for the reinforcing steel yield strength, obtained from the tensile tests and available for the second stage of the assessment, by considering that they are not representative. However, since the material properties have been calculated based on measurements, the expert considers the use of reduced values for partial factors, for concrete and reinforcement according to [22], to be justified.

\section{Probabilistic Analysis}

The structural reliability of the existing reinforced concrete beam cross-section (Figure 4) exposed to the permanent and variable loads specified in Section 3 has been analyzed by using the FORM method. When using probabilistic methods, the reliability of a structure shall be verified in terms of the failure probability according to the following condition $[2,12]$ :

$$
P_{f}=P\left\{g\left(x_{i}\right)<0\right\}<P_{f t}
$$

where $g\left(x_{i}\right)$ is the limit state function of the basic variables $x_{i}$ and $P_{f t}$ is the target probability of failure for a given reference period, here $t_{\text {ref }}=50$ years. In the example of the reinforced concrete beam, the limit state function for the bending resistance in the mid-span crosssection is given as:

$$
g\left(x_{i}\right)=\xi_{R, M} \cdot\left[f_{y} \cdot A_{s} \cdot d-0.5 \cdot \frac{\left(f_{y} \cdot A_{s}\right)^{2}}{b \cdot \eta_{c} \cdot f_{c}}\right]-\xi_{E, M} \cdot\left[M_{g c}+M_{g p}+M_{q}\right]=0
$$

where $M_{g c}, M_{g p}$ and $M_{q}$ are the bending moments due to the self-weight of the beam, the other permanent loads and the variable (imposed) load, respectively. Other variables are explained in previous sections. In a first analysis, the probabilistic models given in Table 3 are used. The resulting design values and sensitivity factors for the basic variables are indicated in Table 12. A probability of failure of $p_{f}=2.86 \times 10^{-3}$ has been obtained, which corresponds to a reliability index $\beta=2.76$. Considering the assumed target reliability index 
of $\beta_{t}=3.8$ (Table 5), the reliability of the beam is insufficient. This confirms the results obtained in first stage of the safety verification by applying the different partial factor approaches (Table 5).

Table 12. Assessment values and sensitivity factors obtained in probabilistic analysis.

\begin{tabular}{cccccc}
\hline \multirow{2}{*}{ Variable } & \multirow{2}{*}{ Unit } & \multicolumn{2}{c}{ 1st Analysis } & \multicolumn{2}{c}{ 2nd Analysis ${ }^{\mathbf{1}}$} \\
\cline { 3 - 6 } & & $\boldsymbol{X}_{\mathbf{a}}$ & $\boldsymbol{\alpha}_{\boldsymbol{X}}$ & $\boldsymbol{X}_{\mathbf{a}}$ & $\boldsymbol{\alpha}_{\boldsymbol{X}}$ \\
\hline$\xi_{R, M}$ & - & 0.97 & 0.2093 & 0.96 & 0.1985 \\
$A_{s}$ & $\mathrm{~mm}^{2}$ & 1954 & 0.0799 & 1951 & 0.0739 \\
$f_{y}$ & $\mathrm{~N} / \mathrm{mm}^{2}$ & 195.2 & 0.3969 & 278.6 & 0.2918 \\
$d$ & $\mathrm{~mm}$ & 538.6 & 0.1795 & 533.5 & 0.1759 \\
$b$ & $\mathrm{~mm}$ & 299.8 & 0.0063 & 299.7 & 0.0089 \\
$f_{c}$ & $\mathrm{~N} / \mathrm{mm}^{2}$ & 24.84 & 0.0515 & 24.43 & 0.0617 \\
$\eta_{c}$ & - & 1.0 & - & 1.0 & - \\
$\xi_{E, M}$ & - & 1.116 & -0.4178 & 1.173 & -0.3962 \\
$M_{g c}$ & $\mathrm{kN} \cdot \mathrm{m}$ & 20.29 & -0.0199 & 20.3 & -0.0146 \\
$M_{g p}$ & $\mathrm{kN} \cdot \mathrm{m}$ & 46.38 & -0.1108 & 46.52 & -0.0811 \\
$M_{q}$ & $\mathrm{kN} \cdot \mathrm{m}$ & 103.44 & -0.7551 & 153.6 & -0.8194 \\
\hline
\end{tabular}

${ }^{1}$ With updated values for $f_{y}$ and $f_{c}$.

To improve the estimate of $\beta$, the updated values for the reinforcing steel yield strength, $f_{y}$, and for the concrete compressive strength, $f_{c}$, indicated in Table 9 are adopted. The probabilistic analysis of the RC beam results in a probability of failure $p_{f}=1.6 \times 10^{-5}$ and the corresponding reliability index increases to $\beta=4.16$, which is higher than the required reliability level expressed by $\beta_{t}=3.8$. Therefore, for the remaining working life the beam can be judged sufficiently reliable for bending resistance. The obtained assessment values, $X_{a}$, and sensitivity factors, $\alpha_{X}$, for the basic variables are also indicated in Table 12. The comparatively low value obtained for the sensitivity factor of $f_{c}$ shows that the concrete compressive strength is not among the most relevant variables with regard to bending failure and more important variables, as $f_{y}$, should be preferably updated. Most effective would be updating the parameters of the variable load $q$, in case corresponding information would be available.

\section{Conclusions}

Rational decision-making on the reliability of existing structures for present and future use should be possible based on a partial factor format equivalent to the format normally applied in the design of new structures. Recently developed studies include approaches for the assessment of existing structures based on the PFM [2,8-10].

In this paper, the assessment of one of the main RC beams of an industrial building, that will be transformed into a cultural centre, was carried out in a round robin exercise, on the application of TS [2], by experts of National Standardization Bodies (NSB) of eight CEN member states. Furthermore, the example was solved by the authors according to the operational rules developed in [9], as well as by applying both partial factors approaches, DVM and APFM, proposed in [10]. All the applied partial factor approaches are suitable for the assessment of existing reinforced concrete structures and allow for taking into account the remaining working life adopted, the target reliability indices assumed in each case and the updated information with site-specific data obtained from in situ inspections, measurements and tests.

The PFM-based assessment was performed in two stages, successively raising the quality of the available information, and was limited to the mid-span cross-section for sake of simplicity. The results of the first stage showed that for none of the applied approaches, the safety for bending resistance was verified. The outcomes for the assessment values of the effects of actions in this stage were quite similar in all cases, whereas for bending resistance significant variation can be observed. The latter could be explained 
by different assumptions for the prior information as well as the procedures adopted for updating the models for material properties, resulting in different characteristic values for these properties.

In the second stage, the reliability of the beam was verified by five of the experts of the NSBs of CEN member states who applied PFM following the indications of the TS [2]. However, due to the same reasons exposed before, the results obtained for the assessment values of resistance again showed a significant variation. Furthermore, the reliability of the beam was also verified by applying the APFM. On the other hand, the application of the procedure from [9] and the DVM [10] revealed that the studied beam does not meet the structural reliability requirements for the remaining service life.

Comparing the two approaches, DVM and APFM, it is apparent that the former enables incorporating the updated information more accurately than the latter. In the DVM, the partial factors are updated by means of the representative values (mean or characteristic) and the respective coefficients of variation, while in the APFM updated information is incorporated only through the coefficients of variation of the variables. Moreover, the APFM establishes limiting values for the coefficients of variation of resistance and load effects, in such a way that the model uncertainties could not become dominant variables, considering that for practical purposes this is not advised. The latter affects the incorporation of updated information and, therefore, may distort the results.

All the considered approaches are based on the use of fixed sensitivity factors, $\alpha_{X}$, according to [3,12], for determining partial factors. However, both the DVM and the APFM, assume that each of the material properties or load effects are dominating for deriving the partial factors for concrete and reinforcing steel resistance, as well as for the actions, permanent or variable. In contrast, normally only one action and one resistance variables are considered dominant whereas the remaining variables are non-dominant [3,12]. This assumption could also distort the results and explain the observed differences.

Finally, the reliability of the beam for bending resistance has been verified by means of a full probabilistic analysis. The findings of the analysis carried out by using the probabilistic models corresponding to the first assessment stage (Table 3) are consistent with the results obtained with all the procedures based on PFM that were applied. A second analysis, applying the updated models for the concrete compressive strength and the reinforcing steel yield strength corresponding to the second stage, showed that the beam reliability is verified, in agreement with the results based on the APFM [10] and those obtained by some of the NSBs. The values obtained for the sensitivity factors show for which variables further updating efforts would be most effective, if needed.

Author Contributions: Conceptualisation, C.L. and P.T.; methodology, C.L. and P.T.; Investigation, C.L.; P.T.; C.Z. and R.H.; writing-original draft preparation, C.L.; writing-review and editing, C.L.; P.T.; C.Z. and R.H. All authors have read and agreed to the published version of the manuscript.

Funding: This research received no external funding.

Conflicts of Interest: The authors declare no conflict of interest.

\section{References}

1. ISO 13822. Basis for Design of Structures—Assessment of Existing Structures; International Organization for Standartization (ISO): Geneva, Switzerland, 2001.

2. CEN/TS 17440. Technical Specification-Assessment and Retrofitting of Existing Structures; CEN/TS 17440; European Committee for Standardization CEN: Brussels, Belgium, 2020; p. 50.

3. EN 1990. Eurocode-Basis of Structural Design; EN 1990:2002; European Committee for Standardization CEN: Brussels, Belgium, 2002.

4. Vrouwenvelder, A.C.W.M.; Scholten, N. Assessment Criteria for Existing Structures. Struct. Eng. Int. 2010, 20, 62-65. [CrossRef]

5. Steenbergen, R.D.J.M.; Vrouwenvelder, A.C.W.M. Safety philosophy for existing structures and partial factors for traffic loads on bridges. HERON 2010, 55, 123-139.

6. Steenbergen, R.D.J.M.; De Boer, A.; Van der Veen, C. Calibration of partial factors in the safety assessment of existing concrete slab bridges for shear failure. HERON 2012, 57, 55-68. 
7. Sýkora, M.; Holický, M.; Marková, J. Verification of existing reinforced concrete bridges using the semi-probabilistic approach. Eng. Struct. 2013, 56, 1419-1426. [CrossRef]

8. Tanner, P.; Lara, C.; Hingorani, R. Seguridad estructural. Una lucha con incertidumbres. Hormigón y Acero 2007, 245, 59-78.

9. Tanner, P.; Lara, C.; Prieto, M. Semi-probabilistic models for the assessment of existing concrete structures. In Proceedings of the Applications of Statistics and Probability in Civil Engineering, ICASP11, Zürich, Switzerland, 1-4 August 2011; pp. $1039-1047$.

10. FIB. Bulletin 80 Partial Factor Methods for Existing Concrete Structures; Fédération Internationale du Béton: Lausanne, Switzerland, 2016; p. 129.

11. Caspeele, R.; Sykora, M.; Alaix, D.L.; Steenbergen, R. The Design Value Method and Adjusted Partial Factor Approach for Existing Structures. Struct. Eng. Int. 2013, 23, 386-393. [CrossRef]

12. ISO 2394. General Principles on Reliability for Structures; ISO 2394:2015(E); International Organization for Standartization (ISO): Geneva, Switzerland, 2015; p. 111.

13. Sykora, M.; Holicky, M. Verification of existing reinforced concrete structures using the design value method. In Proceedings of the Third International Symposium on Life-Cycle Civil Engineering, IALCCE12: Life-Cycle and Sustainability of Civil Infrastructure Systems, Vienna, Austria, 3-6 October 2012; p. 190.

14. Gino, D.; Castaldo, P.; Bertagnoli, G.; Giordano, L.; Mancini, G. Partial factor methods for existing structures according to fib Bulletin 80: Assessment of an existing prestressed concrete bridge. Struct. Concr. 2020, 21, 15-31. [CrossRef]

15. Gino, D.; Castaldo, P.; Bertagnoli, G.; Cimetta, S.; Mancini, G. Assessment of an existing prestressed concrete bridge according to the partial factor method for existing structures (fib Bulletin 80). IOP Conf. Ser. Mater. Sci. Eng. 2019, 603, 022073. [CrossRef]

16. Tanner, P.; Lara, C.; Bellod, J.L.; Sanz, D. "The plastic cathedral": Innovation to extend the service life of a heritage structure. Struct. Concr. 2020, 21, 1425-1440. [CrossRef]

17. Hingorani, R.; Tanner, P. Risk-informed requirements for design and assessment of structures under temporary use. Risk Anal. 2020, 40, 68-82. [CrossRef] [PubMed]

18. Hingorani, R.; Tanner, P.; Zanuy, C. Life safety risk-based requirements for concrete structures in accidental situations caused by gas explosions. Struct. Saf. 2019, 76, 184-196. [CrossRef]

19. Tanner, P.; Hingorani, R. Acceptable risks to persons associated with building structures. Struct. Concr. 2015, 16, 314-322. [CrossRef]

20. Instrucción especial para estructuras de hormigón armado. Available online: https://csic-primo.hosted.exlibrisgroup.com/ primo-explore $/$ fulldisplay?docid=34CSIC_ALMA_DS21139124300004201=34CSIC_VU1=ALL_RESOURCES_scope=default_ tab $=$ es_ES=L (accessed on 12 February 2021).

21. EN 1991-1-1. Eurocode 1: Actions on Structures. Part 1-1: General Actions. Densities, Self-Weight, Imposed Loads for Buildings; EN 1991-1-1:2002; European Committee for Standardization CEN: Brussels, Belgium, 2002.

22. EN 1992-1-1. Eurocode 2: Design of Concrete Structures. Part 1-1: General Rules and Rules for Buildings; EN 1992-1-1:2004; European Committee for Standardization CEN: Brussels, Belgium, 2004. 